\title{
The Influence of Omeprazole on the Dissolution Processes of pH-Dependent Magnetic Tablets Assessed by Pharmacomagnetography
}

\author{
Guilherme A. Soares 1,*DiD, Deivid W. Pires ${ }^{1}$, Leonardo A. Pinto ${ }^{1}$, Gustavo S. Rodrigues ${ }^{1}$, André G. Prospero ${ }^{1}$, \\ Gabriel G. A. Biasotti ${ }^{1}$, Gabriela N. Bittencourt ${ }^{1}$, Erick G. Stoppa ${ }^{1} \mathbb{D}$, Luciana A. Corá ${ }^{2} \mathbb{D}$, Ricardo B. Oliveira $^{3} \mathbb{D}$ \\ and José R. A. Miranda 1 \\ 1 Department of Biophysics and Pharmacology, Institute of Biosciences, São Paulo State University—UNESP, \\ Botucatu 18618-689, São Paulo, Brazil; deivid.pires@unesp.br (D.W.P.); leonardo.antonio@unesp.br (L.A.P.); \\ gustavo.serafim@unesp.br (G.S.R.); andre.prospero@unesp.br (A.G.P.); gabriel_gdab@hotmail.com (G.G.A.B.); \\ ga.nbittencourt@gmail.com (G.N.B.); e.stoppa@unesp.br (E.G.S.); jose.r.miranda@unesp.br (J.R.A.M.) \\ 2 Center of Integrative Sciences, Alagoas State University of Health Sciences-UNCISAL, Maceio 57010-382, \\ Alagoas, Brazil; luciana.cora@uncisal.edu.br \\ 3 School of Medicine of Ribeirão Preto, University of São Paulo, Ribeirão Preto 18618-689, São Paulo, Brazil; \\ rbdolive@fmrp.usp.br \\ check for \\ * Correspondence: guilherme.soares@unesp.br
}

Citation: Soares, G.A.; Pires, D.W.; Pinto, L.A.; Rodrigues, G.S.; Prospero, A.G.; Biasotti, G.G.A.; Bittencourt,

G.N.; Stoppa, E.G.; Corá, L.A.;

Oliveira, R.B.; et al. The Influence of Omeprazole on the Dissolution Processes of $\mathrm{pH}$-Dependent Magnetic Tablets Assessed by

Pharmacomagnetography.

Pharmaceutics 2021, 13, 1274.

https://doi.org/10.3390/

pharmaceutics13081274

Academic Editors: Rachel Smith,

Daniel Markl, Jaehwi Lee and

Cheong-Weon Cho

Received: 25 May 2021

Accepted: 12 August 2021

Published: 17 August 2021

Publisher's Note: MDPI stays neutral with regard to jurisdictional claims in published maps and institutional affiliations.

\begin{abstract}
Pharmacomagnetography involves the simultaneous assessment of solid dosage forms (SDFs) in the human gastrointestinal (GI) tract and the drug plasmatic concentration, using a biomagnetic technique and pharmacokinetics analysis. This multi-instrumental approach helps the evaluation, as GI variables can interfere with the drug delivery processes. This study aimed to employ pharmacomagnetography to evaluate the influence of omeprazole on the drug release and absorption of metronidazole administered orally in magnetic-coated tablets. Magnetic-coated tablets, coated with Eudragit ${ }^{\circledR}$ E-100 (E100) and containing $100 \mathrm{mg}$ of metronidazole, were produced. For the in vivo experiments, 12 volunteers participated in the two phases of the study (placebo and omeprazole) on different days to assess the bioavailability of metronidazole. The results indicated a shift as the $\mathrm{pH}$ of the solution increased and a delay in the dissolution of metronidazole, showing that the $\mathrm{pH}$ increase interferes with the release processes of tablets coated with E100. Our study reinforced the advantages of pharmacomagnetography as a tool to perform a multi-instrumental correlation analysis of the disintegration process and the bioavailability of drugs.
\end{abstract}

Keywords: AC biosusceptometry; Eudragit ${ }^{\circledR}$ E-100; pharmacomagnetography; proton pump inhibitor

\section{Introduction}

The oral route is the simplest, most convenient, patient compliant, and safest drug administration mode [1,2]. Generally, a drug administered orally is in a solid dosage form (SDF), such as gastric soluble tablets. SDFs have the primary objective of providing immediate drug release or promoting release in specific locations to be absorbed in the gastrointestinal (GI) tract [3].

However, drug delivery systems must overcome highly variable physiological and physicochemical conditions throughout the GI tract, including the luminal pH [4-6]. Several factors can modify the gastric environment's $\mathrm{pH}$, especially those related to drug co-administration, such as proton pump inhibitors (PPIs) [7-9]. PPIs (such as omeprazole) inhibit gastric acid secretion in the parietal cells of the stomach. Consequently, PPIs increase the intragastric $\mathrm{pH}>4$, and they can directly interfere with the absorption of drugs taken simultaneously with this type of medication. Studies show that co-administration of 
drugs with omeprazole modifies their pharmacokinetic parameters, such as absorption, bioavailability, distribution, and metabolism [10-15].

In addition to directly affecting absorption and bioavailability, the change in $\mathrm{pH}$ can also change the performance of $\mathrm{pH}$-dependent coating strategies. A common strategy to achieve specificity of $\mathrm{pH}$-dependent drug delivery systems is coating SDFs with polymers with a pH-dependent solubility, such as Eudragit ${ }^{\circledR}$ E-100 (E100) [16-18]. E100 is a cationic polyelectrolyte based on dimethylaminoethyl methacrylate and other neutral methacrylic acid esters. Due to E100's pH-dependence characteristics, this polymer can be used to release the drug in the gastric environment immediately and perform several other interesting applications.

Although in vitro tests performed during the development of formulations are quite effective, in vivo tests are essential to evaluate the behavior of pharmaceutical forms in the human GI tract. It is of paramount importance to implement methods capable of characterizing pharmaceutical forms in vivo. Biomagnetic methods are non-invasive and have been implemented as a viable and promising pharmaceutical research tool, allowing correlations between monitoring the pharmaceutical forms along the GI tract and pharmacokinetic parameters $[19,20]$. Alternate Current Biosusceptometry (ACB) is a biomagnetic technique employed as an alternative method in pharmaceutical research to evaluate the behavior of solid dosage forms in vitro, monitoring their journey in the different segments of the GI tract in vivo. It is also an auxiliary tool for SDFs quality control $[18,20,21]$.

Recently, ACB was proposed in association with pharmacokinetics in an approach called pharmacomagnetography. Pharmacomagnetography consists of relating magnetic monitoring of the pharmaceutical form with the pharmacokinetic parameters and bioavailability of the drug. A previous study showed a successful approach using the ACB system to evaluate the GI transit and pharmacokinetics profile of magnetic enteric-coated tablets and assess the drug delivery and bioavailability [22].

In this context, this study aimed to use this approach to assess the influence of gastric $\mathrm{pH}$ changes caused by treatment with PPI on the process of releasing a model drug administered orally in tablets coated with E100.

\section{Materials and Methods}

\subsection{Materials}

All the materials used in this study were of analytical grade. Manganese ferrite $\left(\mathrm{MnFe}_{2} \mathrm{O}_{4}\right.$; diameter of $\left.50<\phi<75 \mu \mathrm{m}\right)$ was purchased from Ferroxcube, El Paso, TX, USA. Metronidazole, isopropyl alcohol (IPA), acetonitrile, acetone, polyethylene glycol 6000, magnesium stearate, and talc were purchased from Sigma-Aldrich, Santo Andre, Brazil. Microcrystalline cellulose (Microcel $\left.{ }^{\circledR}\right)$ and sodium starch glycolate (Explosol ${ }^{\circledR}$ ) were kindly supplied by Blanver, Taboão da Serra, Brazil. Colloidal silica (Aerosil ${ }^{\circledR}$ ) was purchased from Evonik, São Paulo, Brazil. E100 (Degussa, Rohm Pharma Polymers) was provided by Almapal Tecnologia Validada, Cotia, Brazil.

\section{2. pH-Dependent Magnetic Coated Tablets}

$\mathrm{pH}$-dependent magnetic coated tablets were manufactured to be used in this study, since this formulation was not intended for commercial purposes. The magnetic tablets were obtained by direct compression in a single-punch die set machine (Marconi MA098/C, Piracicaba, Brazil), using a $12 \mathrm{~mm}$ diameter matrix. The tablets were prepared using $500 \mathrm{mg}$ of manganese ferrite microparticles, $100 \mathrm{mg}$ of metronidazole as a model drug, $300 \mathrm{mg}$ of microcrystalline cellulose, $10 \mathrm{mg}$ of magnesium stearate, $50 \mathrm{mg}$ of Aerosil ${ }^{\circledR}$, and $40 \mathrm{mg}$ of Explosol ${ }^{\circledR}$. All the excipients and the drug were mixed and manually compressed at a pressure of $30 \mathrm{kN}$. The tablets were coated by the spray-drying method in a bench-coating machine (LEMAQ, São Paulo, Brazil), with a solution containing Eudragit ${ }^{\circledR}$ E-100 as a $\mathrm{pH}$-dependent coating, maintaining the stability of the tablet and the release of the drug immediately in gastric media. The coating solution was prepared as follows: E100 (50\%, 
$w / w)$ was dispersed in isopropyl alcohol $(25 \%, w / w)$ and acetone $(25 \%, w / w)$. This solution was mixed until all of the polymers were dissolved. Polyethylene glycol 6000 33\% (12.2\%, $w / w)$, as a plasticizer, and talc $(37.8 \%, w / w)$, as a lubricant, were dispersed in isopropyl alcohol $(25 \%, w / w)$ and acetone $(25 \%, w / w)$ and mixed for $10 \mathrm{~min}$. After this procedure, the polyethylene glycol $33 \%$ and talc solution were added to the solution containing the E100 and mixed until it became a homogeneous solution. In the end, this solution was filtered through a $0.5 \mathrm{~mm}$ filter and subsequently applied to the tablets to obtain a $6 \%$ weight gain. The coating process was carried out at an inlet temperature of $35 \pm 5{ }^{\circ} \mathrm{C}$, while the outlet temperature was $30 \pm 4{ }^{\circ} \mathrm{C}$. The spray rate of the coating solution was $15 \mathrm{~mL} / \mathrm{min}$, and the atomization pressure was 1.5 bar. When the tablets reached a gain of $6 \%(w / w)$ of the initial weight, they were placed in an oven at a temperature of $40{ }^{\circ} \mathrm{C}$ for 24 $\mathrm{h}$ for drying and maturation of the applied polymer. In the present study, magnetic-coated tablet formulations were tested according to the outline in the US Pharmacopeia. Therefore, the average weight, hardness, and friability were assessed for all tablet formulations. The disintegration and dissolution tests are provided in the manuscript.

The average weight was calculated by weighing the tablet batches individually. We used a $10^{-4} \mathrm{~g}$ resolution analytical balance. This test was carried out to check the uniformity of the tablets in each formulation, in which the acceptable criteria variation limit was $\pm 5 \%$.

The hardness test was performed using a durometer Dr. Schleuniger model 6D (Pharmatron, Westborough, Ma, EUA). The test results were obtained and represented by six assessments for each tablet, in agreement with U.S. Pharmacopeia (USP), which sets the minimum acceptable hardness in the 4 to 10 kilopounds $(\mathrm{Kp})$ range.

Regarding friability, the test allowed the determination of the resistance of the tablets to abrasion when subjected to the mechanical action of specific equipment. The friability of the tablets was determined using an automated system, Friabilometer EF-2 (Nova Ética, São Paulo, Brazil), at $25 \mathrm{rpm}$ for four minutes. After this, they were weighed, and the weight loss (\%) was calculated according to the USP specifications, in which the friability must not exceed $1.5 \%$ of tablet weight. The percentage of weight loss was calculated with the Equation (1):

$$
\text { Friability }(\%)=\frac{\text { initial weight }- \text { final weight }}{\text { initial weight }} \times 100
$$

\subsection{Alternate Current Biosusceptometry}

AC Biosusceptometry is a biomagnetic technique based on using induction coils to magnetize and detect the magnetization of magnetic materials. This study employed two ACB setups: single and multichannel systems. The single-channel ACB (SC-ACB) has one pair of induction and detection coils $(\phi=2.9 \mathrm{~cm})$, and the multichannel ACB (MC-ACB) system has one pair of induction coils $(\phi=11 \mathrm{~cm})$ and seven pairs of detection coils $(\phi=$ $3.5 \mathrm{~cm}$ ). The induction coils of the SC-ACB are supplied with $500 \mathrm{~mA}$ and the MC-ACB with $150 \mathrm{~mA}$, both with $\mathrm{AC}$ voltage at $10 \mathrm{kHz}$, and the signal is acquired at a rate of $20 \mathrm{~Hz}$ in a LabView environment. The ACB system presents a high temporal resolution, which depends only on the acquisition frequency and the A/D board capability. Here, the temporal resolution obtained by both ACB setups was $50 \mathrm{~ms}$.

Regarding the spatial resolution, the obtained SC-ACB and MC-ACB spatial resolutions in these experiments were in the order of millimeters and centimeters, respectively. In in vivo situations, in which the $A C B$ detection surface was positioned at around $4 \mathrm{~cm}$ until the gastric projection, the spatial resolution decreased, and the SC-ACB and MC-ACB were $2 \mathrm{~cm}$ and $4 \mathrm{~cm}$, respectively. The SC-ACB had a sensitivity limit of about $\mathrm{mg}$ per $\mathrm{cm}^{3}$ and the MC-ACB of about $\mathrm{g}$ per $\mathrm{cm}^{3}$.

Due to its versatility, the SC-ACB was employed to evaluate the performance of the tablets' transit and determine the value of the Gastric Retention Time (GRT, the time interval between ingestion and elimination of the stomach) of the coated magnetic tablets by manually scanning a given region of interest [21]. MC-ACB is suitable for simultaneous signal acquisition in seven different points of space. This modality was used to obtain 
magnetic images in real-time $[20,23]$ and evaluate the disintegration process of the coated magnetic tablets. Figure 1 presents the two ACB systems and their operation principles.
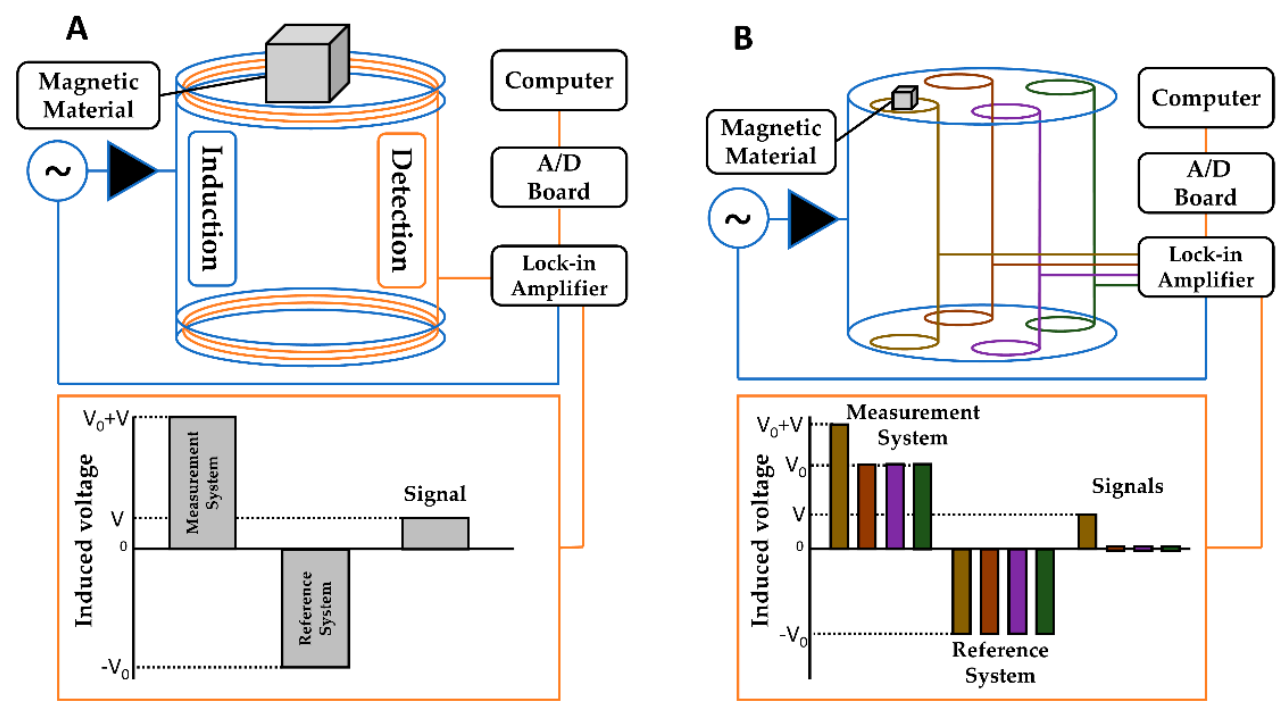

Figure 1. Functional diagram of the ACB setup and its principle of operation. (A) Schematic representation of the SC-ACB and (B) Schematic representation of MC-ACB with multiple detection coils.

\subsection{In Vitro Studies}

\subsubsection{USP 2 Dissolution Procedure}

The dissolution studies of the coated magnetic tablets were carried out in a USP dissolution test apparatus 2 (paddle method, $50 \mathrm{rpm}, 37 \pm 0.5^{\circ} \mathrm{C}$ ). A simulated gastric fluid with different $\mathrm{pH}$ values was used as a dissolution medium. The media volume was $900 \mathrm{~mL}$. An exact sample volume $(1 \mathrm{~mL})$ was withdrawn and replaced with a fresh dissolution medium at times: $0.5,1,2,3,4,5,10,15,20,25,30,45,60,75,90,105$, and $120 \mathrm{~min}$. The time intervals were projected to evaluate the initial metronidazole release at all $\mathrm{pH}$ values. All samples were filtered through a cellulose acetate membrane of $0.22 \mu \mathrm{m}$.

All tests were performed in sextuplicate, and samples were analyzed with a UVspectrophotometer-Ultrospec 2000Spectrophotometer (Pharmacia Biotech, Uppsala, Sweden) at $277 \mathrm{~nm}(\mathrm{pH} 1.2$ and $\mathrm{pH} 2.0)$ or $318 \mathrm{~nm}(\mathrm{pH} 3.0$ and $\mathrm{pH} 4.5)$.

Metronidazole concentrations were calculated using calibration profiles based on absorbance versus concentration curves, which were previously standardized. The lag time $\mathrm{T}_{\text {lag }}$ (in $\mathrm{min}$ ) was calculated as the time point at which metronidazole was first detected in the dissolution medium.

The dissolution efficiency (DE) was calculated as the percentage ratio between the area under the dissolution curve up to time $\mathrm{t}\left(\mathrm{AUC}_{0-\mathrm{t}}\right)$ and the area of the rectangle described by $100 \%$ dissolution at the same time point $\left(A_{\mathrm{t}}\right)$, and it was defined as follows [24] in Equation (2):

$$
\mathrm{DE}=\frac{\mathrm{AUC}_{0-\mathrm{t}}}{A_{\mathrm{t}}}
$$

We established a validation protocol for the metronidazole characterization and quantification by UV-spectrophotometer. This validation was based on assessing a series of validation parameters, such as the Limit of detection (LOD), Limit of quantification (LOQ), sensitivity, accuracy, and linearity. For the UV-spectrophotometer and our metronidazole reference used, we found a LOD of $0.070453 \mu \mathrm{g} / \mu \mathrm{L}$ and a LOQ of $0.234843 \mu \mathrm{g} / \mu \mathrm{L}$. The results demonstrated the development and validation for our UV-spectrophotometer quantification of metronidazole under the International Harmonization Conference (ICH, 2005) and the National Agency of Sanitary Vigilance (ANVISA, 2003) guidelines. According to 
the results, the method is linear, specific, and it can accurately measure the drug in the selected range with low uncertainty.

\subsubsection{Multichannel ACB System Measurements (MC-ACB)}

Using a squared glass vessel with the same dissolution mediums as used for the USP 2 dissolution procedure, we designed an experiment to investigate the suitability of the MC-ACB system, to assess the $\mathrm{pH}$ dependence of the tablets' E100 coat dissolution through magnetic signal reconstructed images. The glass vessel was positioned in front of the MC-ACB system at an axial distance of $3 \mathrm{~cm}$, and then, the coated magnetic tablets were introduced into the solution, and signals were acquired for $30 \mathrm{~min}$. This phase was performed in sextuplicate. As demonstrated in our previous studies, the area in the magnetic images obtained from the signals was evaluated to determine the disintegration process $[18,25]$. The magnetic image reconstruction and analysis are further described in the 'magnetic data analysis' section.

\subsection{In Vivo Study Protocol}

Twelve healthy volunteers (six males, six females, aged between 20 and 27 years, body weight between 50 and $80 \mathrm{~kg}$, and $\mathrm{BMI}<22 \mathrm{~kg} / \mathrm{m}^{2}$ ) were enrolled in this study. General exclusion criteria included pregnancy, smoking, abdominal surgery, diabetes, other chronic endocrine disorders affecting GI motility, and treatment with prokinetics, anticholinergics, opiates, or macrolide drugs. Participants remained moderately active during the study day and received standardized meals at $2 \mathrm{~h}, 4 \mathrm{~h}$, and $6 \mathrm{~h}$ post-dose [22].

This was a single-center, randomized, double-blind, comparative study to evaluate the pharmacokinetic and magnetic behavior of coated magnetic tablets containing metronidazole before (placebo) and after omeprazole administration. There was a 7-day period separating both treatments for the same subject. Before the experiment, the volunteers received either $40 \mathrm{mg}$ of placebo or $40 \mathrm{mg}$ of immediate-release omeprazole at night. After fasting overnight, 30 minutes before the beginning of the experiment, all volunteers received another dosage of the same tablet as previously administered. The subjects swallowed the E100-coated magnetic tablets with $200 \mathrm{~mL}$ of water, and the magnetic signals were recorded for $30 \mathrm{~min}$ through the MC-ACB. The volunteers were standing, and the system was positioned on the volunteers' abdomens, in the region corresponding to the gastric projection according to external anatomical references [25]. After continuous recording with the $\mathrm{MC}-\mathrm{ACB}$ system, mapping from the abdominal surface was performed every $30 \mathrm{~min}$ using the SC-ACB system to locate the coated magnetic tablet and determine the GRT.

Blood samples were obtained at 30 (pre-dose), 3, 6, 9, 12, 15, 18, 21, 24, 27, 30, 45, 60, $90,120,150,180,210,240$, and 300 min after tablet administration to assess the absorption profile of metronidazole. The samples were immediately centrifuged, and the serum was stored at $-80^{\circ} \mathrm{C}$ until analysis.

This study was approved according to the protocol approved by the Ethics in Research of the Medical School, State University of São Paulo (UNESP). It was conducted under the Declaration of Helsinki and its revisions. All volunteers gave written informed consent before the study. (Certificate of Presentation for Ethical Appreciation: 41563015.3.0000.5411, Committee's technical opinion number: 986486, Data of Approval: 4 May 2015).

\subsection{Pharmacokinetic Analysis}

The metronidazole quantification in serum samples was performed using ultrahigh-performance liquid chromatography (UHPLC) through an Acquity H Class system equipped with a UV-vis $(\lambda=277 \mathrm{~nm})$ Acquity UPLC Photodiode Array (Waters ${ }^{\circledR}$, Milford, CT, USA). The metronidazole extraction was performed with a previously established protocol [26]. Briefly, $2 \mathrm{~mL}$ of acetonitrile was added to $500 \mu \mathrm{L}$ of serum and mixed for $2 \mathrm{~min}$. Samples were then centrifuged at $4500 \mathrm{rpm}$ at $4{ }^{\circ} \mathrm{C}$ for $10 \mathrm{~min}$, and the supernatant was transferred to a $15 \mathrm{~mL}$ tube, subsequently frozen at $-80^{\circ} \mathrm{C}$, and lyophilized overnight. 
The lyophilized samples were reconstituted on the following day in $200 \mu \mathrm{L}$ of a solution of water/methanol $(90: 10, v / v)$, and then centrifuged for $10 \mathrm{~min}$ at $4{ }^{\circ} \mathrm{C}$ and $14,000 \mathrm{rpm}$. The sample measurements were conducted in the reverse-phase using an Acquity UPLC ${ }^{\circledR}$ BEH C18 column $\left(1.7 \mu \mathrm{m}, 2.1 \times 50 \mathrm{~mm}\right.$, Waters ${ }^{\circledR}$, Milford, CT, USA), with an automatic injector, maintained at $25 \pm 1{ }^{\circ} \mathrm{C}$. The mobile phase was eluted in an isocratic way in a flow of $0.5 \mathrm{~mL} / \mathrm{min}$ and composed of water/acetonitrile $(90: 10, v / v)$.

The following pharmacokinetic parameters were obtained: $\mathrm{T}_{\text {lag }}$, defined as the time at which the first detection of metronidazole in plasma occured; $C_{\max }$, defined as the maximum plasma concentration of metronidazole; $\mathrm{T}_{\max }$, defined as the time taken to reach $\mathrm{C}_{\max }$; and $\mathrm{AUC}_{0-300}$, defined as the area under the plasma concentration curve versus time, from time $t=0$ to $t=300 \mathrm{~min}$.

\subsection{Magnetic Data Analysis}

The magnetic signals recorded by the MC-ACB system were obtained as a time series matrix, and magnetic images were reconstructed by fitting the data of each sensor to the system transfer function. Image processing for quantification included the spline method interpolation, background subtraction, brightness and contrast adjustment, and segmentation. The segmentation quantified the number of pixels in the determined region of interest (ROI) [25].

The coated magnetic tablets' in vitro and in vivo disintegration processes were characterized by a magnetic marker (MM) transition to a magnetic tracer (MT). In the magnetic images, the MM is represented as a delineated point, while the spreading of the magnetic material characterizes the MT, thus increasing the imaging area. The onset of the disintegration process was calculated as the meantime disintegration $\left(T_{50}\right)$, which represented a $50 \%$ increase of pixels in the imaging area [27]. In the case that the imaging area variation was less than $50 \%$ during the 30 min of magnetic signal acquisition, $\mathrm{T}_{50}$ was defined as not available, since a magnetic measurement was performed within this 30 -min interval. It is worth mentioning that the interval time of $\mathrm{T}_{50}$ was determined according to the protocol adopted using MC-ACB [21,28].

The SC-ACB mapping was performed to verify if the tablets were in the stomach, through signal intensity to quantify the GRT [21]. An SC-ACB scan could also be used to assess the behavior of magnetic coating tablets to determine gastric emptying.

\subsection{Statistical Analysis}

The magnetic signals were analyzed in MatLab (Mathworks, Natick, MA, USA) and Origin (Version 2016, OriginLab Corporation, Northampton, MA, USA), and the data are presented as the mean \pm standard deviation. The disintegration process and drug dissolution test of the coated magnetic tablets obtained in vitro at different $\mathrm{pH}$ mediums were compared by one-way analysis of variance (ANOVA) followed by Tukey's multiple comparison test. In vivo, magnetic and pharmacokinetic parameters between both treatments were compared using the paired Student $t$-test. Values of $p<0.05$ were considered to be statistically significant. All data analysis and statistics were performed with GraphPad Prism (GraphPad Software, La Jolla, CA, USA).

\section{Results}

\subsection{Tablet Quality Control Assays}

The tablet quality control assays recommended by USP allowed the evaluation of the physical characteristics regarding the uniformity and properties of mechanical resistance, besides the average weight of non-coated tablets. The average mass $(1.004 \pm 0.003 \mathrm{~g})$, the average diameter $(12.12 \pm 0.01 \mathrm{~mm})$, and average height $(6.08 \pm 0.04 \mathrm{~mm})$ adhered to the maximum variation of $5 \%$ allowed. The friability and hardness test results were $0.18 \%$ and $6.43 \pm 0.74$, respectively. Both results met the USP recommendations. 


\subsection{In Vitro Studies}

A representative plot of the metronidazole release percentage in time for different values of $\mathrm{pH}$ dissolution media is shown in Figure 2. Even though $100 \mathrm{mg}$ of metronidazole release was observed for all $\mathrm{pH}$ mediums during the evaluation, a positive shift (in time) was observed as the $\mathrm{pH}$ increased. Based on individual dissolution profiles, $\mathrm{T}_{\text {lag }}$ and $\mathrm{DE}$ were calculated, and the results are expressed in Table 1. The $\mathrm{pH} 3.0$ dissolution media resulted in an increased $\mathrm{T}_{\text {lag }}$ in comparison to $\mathrm{pH} 1.2$, whereas the $\mathrm{pH} 4.5$ dissolution medium delayed the $\mathrm{T}_{\text {lag }}$ in comparison to all other $\mathrm{pH}$ dissolution media. The $\mathrm{DE}$ values showed no statistically significant difference among the different $\mathrm{pH}$ dissolution media. These results were expected due to the $\mathrm{pH}$ dependence of the E100 coating.

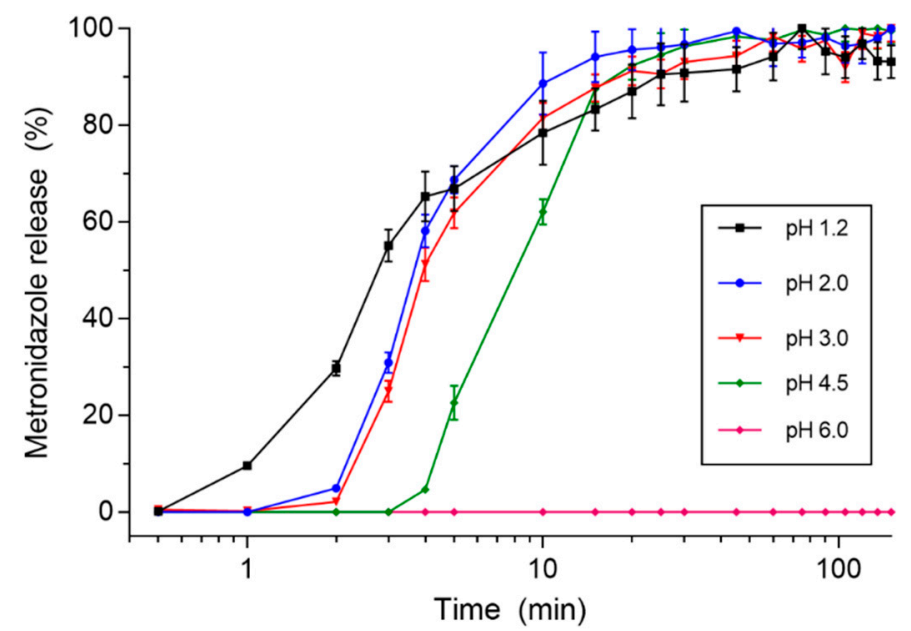

Figure 2. Metronidazole's in vitro release profile versus time for distinct $\mathrm{pH}$ mediums. $(n=6)$.

Table 1. Lag time $\left(\mathrm{T}_{\mathrm{lag}}\right)$ and dissolution efficiency (DE) for coated magnetic tablets in different $\mathrm{pH}$ dissolution mediums $(n=6)$.

\begin{tabular}{|c|c|c|c|c|}
\hline & pH 1.2 & pH 2.0 & pH 3.0 & pH 4.5 \\
\hline $\mathrm{T}_{\text {lag }}(\min )$ & $0.58 \pm 0.20$ & $1.16 \pm 0.40$ & $1.33 \pm 0.52^{a}$ & $3.16 \pm 0.40^{a, b, c}$ \\
\hline DE (\%) & $90.93 \pm 8.11$ & $94.21 \pm 4.55$ & $92.21 \pm 2.51$ & $92.50 \pm 5.08$ \\
\hline
\end{tabular}

A representative plot of the imaging area (pixels) versus time for distinct $\mathrm{pH}$ mediums obtained by MC-ACB images is shown in Figure 3. As observed in Figure 1, an increase in the $\mathrm{pH}$ value resulted in a positive shift in the time for image area growth. Table 2 presents the quantification of onset disintegration $\left(\mathrm{T}_{50}\right)$ for each $\mathrm{pH}$. The $\mathrm{pH} 2.0$ medium delayed the onset of disintegration in comparison to $\mathrm{pH} 1.2$. The $\mathrm{pH} 3.0$ medium resulted in a delayed $\mathrm{T}_{50}$ in comparison to $\mathrm{pH} 1.2$ and 2.0, whereas $\mathrm{t}_{50}$ values for $\mathrm{pH} 4.5$ were delayed in comparison to $\mathrm{pH} 1.2,2.0$, and 3.0. All coated magnetic tablets were disintegrated entirely during the measurement time, regardless of the $\mathrm{pH}$ value. The $\mathrm{T}_{\text {lag }}$ and $\mathrm{T}_{50}$ values obtained in the USP 2 dissolution procedure and MC-ACB images showed a Pearson's correlation coefficient of 0.83 , representing good linearity between the methods [29]. With this, the MC-ACB imaging method showed effectiveness in assessing the influence of medium $\mathrm{pH}$ in the coat dissolution in vitro process and suggests the suitability of using magnetic images to analyze the disintegration process for in vivo measurements. 


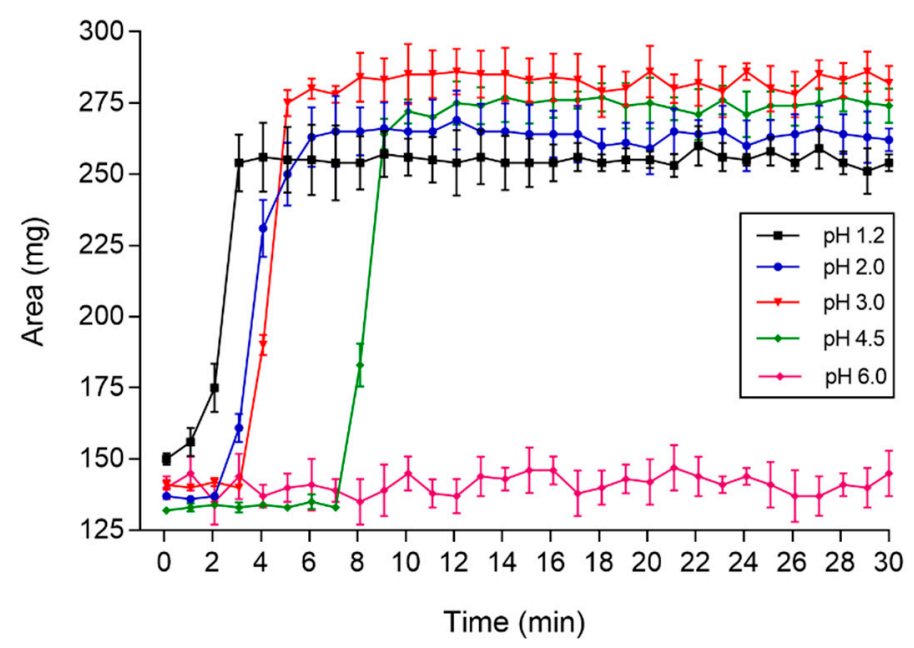

Figure 3. Image area of the coated magnetic tablet versus time for distinct $\mathrm{pH}$ mediums employing the MC-ACB $(n=6)$.

Table 2. The onset of the disintegration process $\left(t_{50}\right)$ for distinct $\mathrm{pH}$ mediums $(n=6)$.

\begin{tabular}{ccccc}
\hline & pH 1.2 & pH 2.0 & pH 3.0 & pH 4.5 \\
\hline $\mathrm{t}_{50}(\mathrm{~min})$ & $2.19 \pm 0.10$ & $3.03 \pm 0.18^{\mathrm{a}}$ & $4.01 \pm 0.15^{\mathrm{a}, \mathrm{b}}$ & $9.54 \pm 1.42^{\mathrm{a}, \mathrm{b}, \mathrm{c}}$ \\
\hline $\mathrm{a}_{p<0.05}$ in comparison to $\mathrm{pH} 1.2 .{ }^{\mathrm{b}} p<0.05$ & in comparison to $\mathrm{pH}$ & $2.0 .{ }^{\mathrm{c}}{ }^{2} p<0.05$ in comparison to $\mathrm{pH}$ 3.0.
\end{tabular}

In vitro studies may be considered an alternative to in vivo pharmacokinetic studies. In vitro dissolution tests can be an essential tool for the pharmaceutical development of solid oral dosage forms, either generic or new drugs. Depending on the characteristics of the intended product and the performance in vitro, the results may be required for waiving the regulatory requirement for in vivo Bioavailability (BA) and Bioequivalence (BE) studies [30]. Although in vivo studies are vital in drug development, the predictive dissolution methodology eliminates unnecessary steps involving volunteers' exposure in clinical studies, reducing financial expenses [31].

The ACB system's assessment through the acquisition of magnetic signals of tablets is a valuable methodology to characterize the tablets' performance in vitro and in vivo in the GI tract. Thus, this approach is interesting for in vitro investigations, and it could consolidate future studies aiming to obtain biowaivers for new and generic drugs. It is worth noting that the ACB system is an alternative tool, like other methodologies, that can carry out a non-invasive analysis to assess the performances of drug formulations. Although the ACB does not provide insights into the drugs' molecular state and chemical stability, the association with spectroscopy methods, such as Raman spectroscopy and near-infrared spectroscopy (NIR), may be very interesting.

The methodologies have been applied to the advanced characterization of drug delivery systems, allowing quality assessment of tablets by non-destructive assay.

In addition, nuclear magnetic resonance (NMR) has presented itself as a suitable technique for obtaining information for developing controlled-release systems due to its nondestructive and noninvasive aspects.

\subsection{In Vivo study Protocols}

Table 3 shows the pharmacokinetics and quantified parameters of the magnetic images of each volunteer. After administering the placebo, the E100 coating of the magnetic tablets was successfully dissolved in all volunteers during the MC-ACB measurement (30 $\mathrm{min})$; the expected fasting gastric $\mathrm{pH}$ was approximately $\mathrm{pH} 2.0$ [32]. In contrast, the results obtained after omeprazole administration showed that in $75 \%$ of volunteers $(2,3,4,5,6,8,9,10$, and 11), the coated magnetic tablets remained intact for $30 \mathrm{~min}$ in gastric fluid, as a result of the increased $\mathrm{pH}$. In $56 \%$ of cases (volunteers 2, 3, 5, 8, and 11), no metronidazole was detected 
in their plasma samples during the $300(5 \mathrm{~h})$ min of measurements. In the other $44 \%$ of cases (volunteers 4, 6, 9, and 10), metronidazole was detected in their plasma samples after the end of the MC-ACB signal acquisition (i.e., $30 \mathrm{~min}$ after administration). For these cases, the $\mathrm{T}_{50}$ was considered as not available. Although the results indicated an increasing trend in several volunteers, the mean of the $\mathrm{T}_{\text {lag }}$ was not significantly different between the control and omeprazole groups, mainly due to the variation between individuals. For example, there was no release of metronidazole in five volunteers, which prevented a comparative group analysis. Furthermore, the individual values in Table 3 show that $T_{\max }$ and $C_{\max }$ did not present differences. Regarding $\mathrm{C}_{\max }$, the results were in agreement with the fact that metronidazole does not undergo inactivation under $\mathrm{pH}$ variations [33]. On the other hand, the administration of omeprazole induced a significantly lower metronidazole bioavailability response, which was significantly lower at intervals of $\mathrm{AUC}_{0-60 \min }(p=$ $0.001)$ and $\mathrm{AUC}_{0-300 \mathrm{~min}}(p=0.05)$. As the AUC indicated significant differences in the extent to which the drug becomes available in the bloodstream, the effect of omeprazole once co-administered with E100-coated tablets was evident in most subjects.

The assessment of GRT values by SC-ACB mapping of the tablets, combined with the pharmacokinetic parameters, showed that pharmacomagnetography analysis is crucial for obtaining a complete understanding of the drug release process, and it cannot be assessed with a one method evaluation.

For example, in volunteer 6, the coated magnetic tablet remained intact in the stomach for $120 \mathrm{~min}$ (GRT data), and the $\mathrm{T}_{\text {lag }}$ obtained was $150 \mathrm{~min}$ in the omeprazole treatment. In this case, we can be sure that the coated tablet did not dissolve in the stomach, based on the magnetic data collected. Therefore, pharmacomagnetography analysis may state that the coating was dissolved or that the tablet was not in the stomach.

In the omeprazole treatment of volunteer 6, the metronidazole was probably released in the small intestine due to peristaltic movements inducing fissures in the tablet's coating. As metronidazole has high solubility and intestinal permeability, the absorption could have occurred at the same release site, which a previous study endorsed.

Table 3 shows that inter-individual biological variability data interfered with our analysis. We obtained profiles in which the administration of omeprazole did not provide any effect on $\mathrm{pH}$ increase. In volunteer 7 , for example, $\mathrm{T}_{\text {lag }}$ and $\mathrm{T}_{50}$ indicated values in line with the Control Phase parameters, likely due to the non-increased $\mathrm{pH}$ following omeprazole. On the other hand, we observed cases in which the magnetic tablet was directly emptied, neither released in the stomach, nor absorbed at any site of the TGI. The parameters of volunteers 2 and 3 suggest these situations; most of the parameters $\mathrm{T}_{\text {lag }} \mathrm{T}_{\max }, \mathrm{C}_{\max }, \mathrm{AUC}_{0-60}$, and $\mathrm{AUC}_{0-300}$ presented no value. Thus, we concluded from the GRT data (40 $\mathrm{min})$ that the magnetic tablet was quickly emptied. [34]. Katz et al. (2001) [35] reported a large inter-subject variation of intragastric $\mathrm{pH}$ after administration of omeprazole $20 \mathrm{mg}$, which is the crucial factor of $\mathrm{pH}$-dependent coating performance. Even though no intragastric $\mathrm{pH}$ measurements were performed in this work, the data strongly suggest that, in the cases in which no metronidazole was found in the plasma after administration of omeprazole, the intragastric $\mathrm{pH}$ was likely above 5 , which is the upper limit for E100 solubility. 


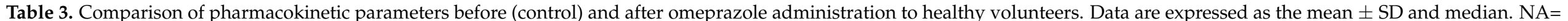
not available ${ }^{*} p<0.05$ vs. control; ${ }^{* *} p<0.001$.

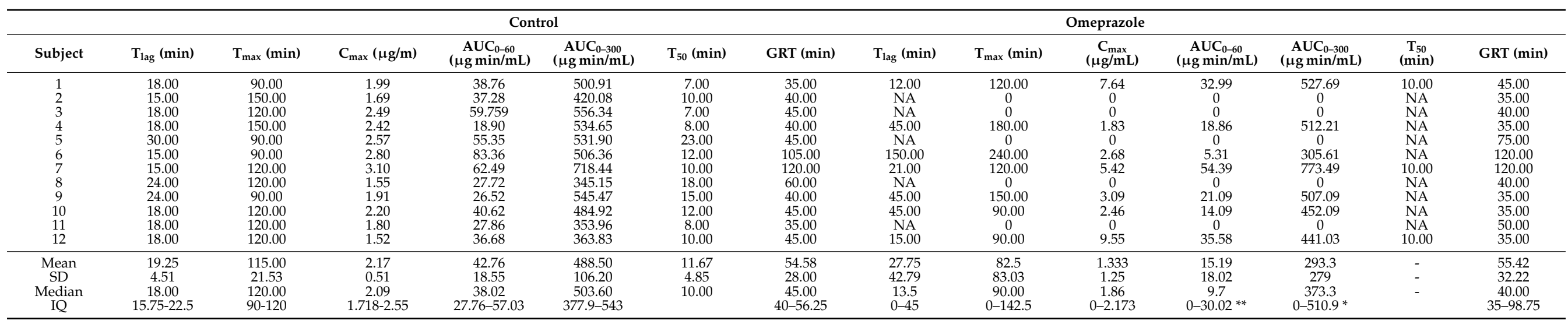


According to the Biopharmaceutical Classification System (BCS), metronidazole is a class I drug, presenting high solubility and high intestinal permeability, which may show in plasma after some time, even with incorrect release sites. The pharmacokinetics of metronidazole are also stable after intravenous or oral administration of omeprazole; even if the $\mathrm{pH}$ of the dissolution medium increases, the drug's solubility rate does not decrease $[33,36]$. Future studies may address the effects of omeprazole administration concomitantly with BCS class II or IV drugs, which will present a low intestinal permeability. Even considering that many drugs have low permeability regardless of PPIs, it is important to properly evaluate the potential interaction and clinical relevance of co-administration with gastric $\mathrm{pH}$-elevating agents since it is common for cancer patients to use these agents, for example. Therefore, studies aiming to assess anticancer availability impacts are essential for determining less potent PPIs or medical strategies to use concomitant PPIs with any drug $[37,38]$. Pharmacomagnetography analysis in these cases (BCS class II and IV drugs) would be interesting in order to assess the location of drug absorption. Regarding BCS class II drugs, there have been broad investigations of the Hedgehog (Hh) pathway [39,40], which have yielded US FDA approval of a few Hh inhibitors (Hh-I) as promising alternative treatments for basal cell carcinomas [41]. Sonidegib, an example of a Hh-I, is classified as a BCS class II drug and has pH-dependent aqueous solubility, with lower solubility at higher $\mathrm{pH}$ levels. Several studies have been performed to assess the influence of PPIs on this inhibitor. In some of these, when coadministered with esomeprazole, the (S)isomer of omeprazole, the AUC and the $\mathrm{C}_{\max }$ of Sonidegib was decreased by 32 to $38 \%$, respectively [42]. Another study highlighted the challenge for scientists aiming to offer new cancer therapies that are not susceptible to acid-reducing agents (ARAs), including PPIs [43].

Infection of the stomach caused by Helicobacter pylori infections is responsible for most peptic ulcers and chronic gastritis and is usually treated with triple therapies, which consist of omeprazole and amoxicillin with either clarithromycin or metronidazole, if the patient is allergic to penicillin and derivates [44]. Both clarithromycin and metronidazole have a bitter taste $[45,46]$; therefore, coating formulations, such as E100, may be used for taste masking [47-49]. The results presented here highlight the importance of avoiding a pH-dependent coating in cases when omeprazole is administered concomitantly. Moreover, PPIs are widely prescribed for all gastric $\mathrm{pH}$ control cases, even when their benefit is considered low or even potentially harmful with adverse outcomes, particularly for patients taking an antiviral. Figure 4 shows examples of the magnetic images and pharmacokinetic analysis of the coated magnetic tablet administered (volunteer 3 ) after the placebo. Immediately after the administration (Figure $4 \mathrm{~A}, \mathrm{t}=0 \mathrm{~min}$ ), the tablet was observed as a well-defined circular region point, since the coating was initially intact. At the end of the measurement (Figure $4 \mathrm{~B}, \mathrm{t}=30 \mathrm{~min}$ ), the coating was successfully dissolved, which was shown by the spreading of the magnetic material increasing the image area. The area of the magnetic image and serum metronidazole concentration are shown in Figure 4E. Since the drug is released after coat dissolution, the increase of the metronidazole plasmatic concentration after area variation in the magnetic image suggests that ACB was able to assess the coat dissolution and tablet disintegration in vivo.

Magnetic images and pharmacokinetic analysis after administration of omeprazole for the same volunteer (3) are shown in Figure 5. As expected, initially (Figure 5A, $t=$ $0 \mathrm{~min}$ ), the coating of the tablet was intact. However, even at $t=30 \mathrm{~min}$ after administration (Figure 5D), the coating remained intact with omeprazole administration. Neither the magnetic area nor the metronidazole concentration showed an increase during the measurement time, suggesting that the coated magnetic tablet remained intact for this volunteer. As one may observe from Table 3, volunteer 3's data shows that no metronidazole was detected in the plasma during the $300 \mathrm{~min}$ measurements after the omeprazole administration. 

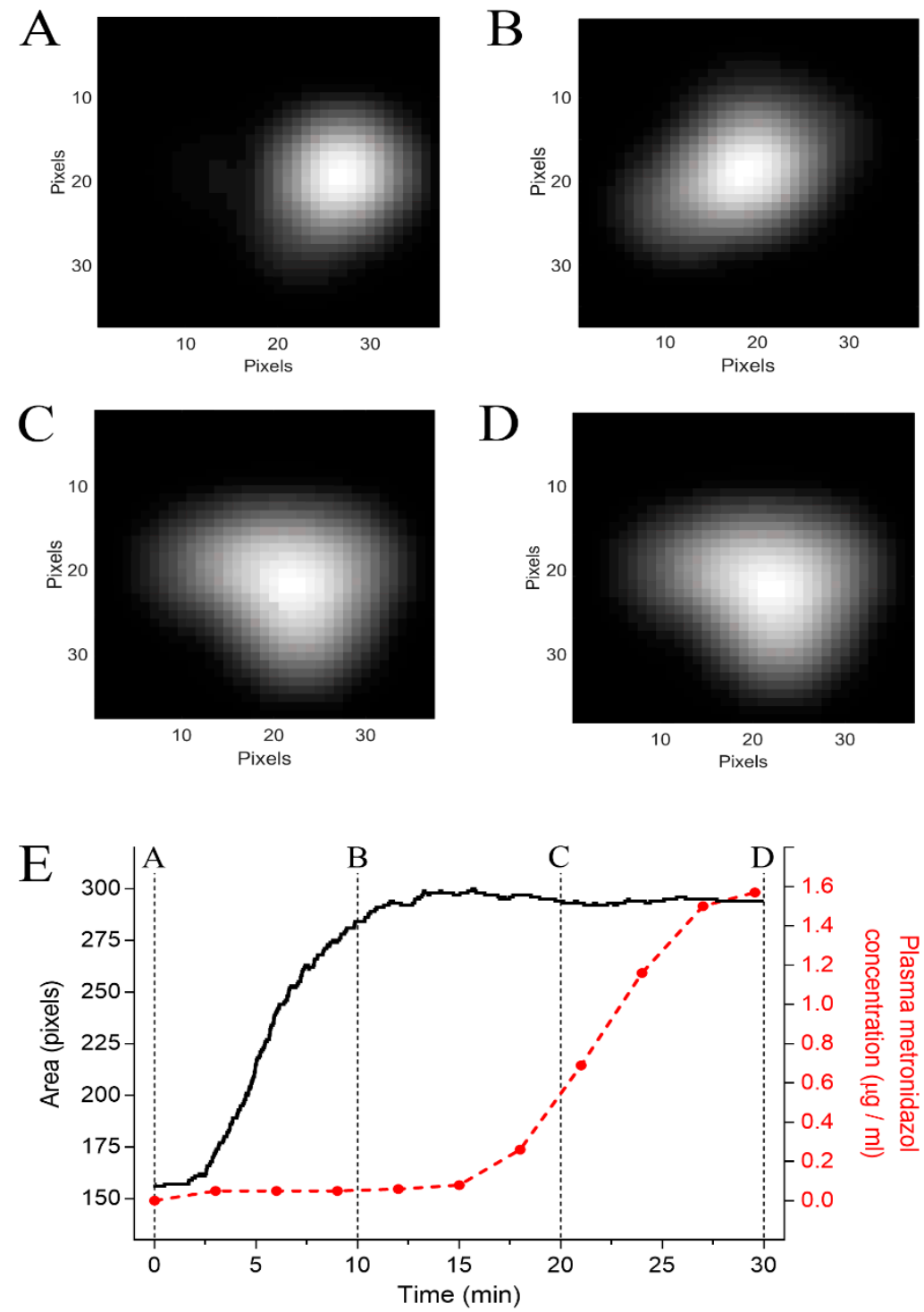

Figure 4. Pharmacomagnetography monitoring of the coated magnetic tablet after administration of the placebo. (A) Magnetic images at $t=0 \mathrm{~min},(\mathbf{B}) \mathrm{t}=10 \mathrm{~min},(\mathbf{C}) \mathrm{t}=20 \mathrm{~min}$, and $(\mathbf{D}) \mathrm{t}=30 \mathrm{~min}$ after coated magnetic tablet administration. (E) Quantification of the magnetic area and metronidazole concentration, the dotted lines indicate the time points in which A, B, C, and D were captured.

Our pharmacomagnetography data indicate the influence on metronidazole's bioavailability of omeprazole concomitant administration, provoking an irregular drug absorption. We observed three different situations regarding the effects of omeprazole administration through our data of the omeprazole administration phase.

Likely due to the intra-individual biological variation, the omeprazole did not increase the $\mathrm{pH}$ elevation, which is endorsed by the pharmacokinetic parameters being very similar to the Control Phase of volunteers 1, 7, and 12. Other volunteers, such as 4, 6, 9, and 10 , presented a delayed-release and lower bioavailability, represented by Tlag and the AUC parameters, respectively. However, due to the delayed-release (more than $30 \mathrm{~min}$ of monitoring by $\mathrm{MC}-\mathrm{ACB}$ ), the $\mathrm{T}_{50}$ was not quantified (not available).

On the other hand, the pharmacokinetic parameters of volunteers 2, 3, 5, 8, and 11 imply that the magnetic-coated tablets were entirely emptied, with no release and consequently no absorption (even in the small intestine). The pharmacomagnetography analysis employing the MC-ACB system presented several advantages compared to other biomagnetic techniques used for this purpose. The main techniques use a superconducting 
quantum interference device (SQUID), which requires a magnetically shielded room to perform measurements. This restriction makes the technique more expensive and less portable and restricts its biomedical applications. In this context, other methods have been applied to evaluate, in vivo, the behavior of an oral solid dosage form in the gastrointestinal tract. These visualization methods include $\gamma$-scintigraphy, X-ray imaging, and magnetic resonance imaging. However, as with the SQUID, the drawbacks of these techniques include large radiation exposure, demand for a shielded room, high cost associated with maintenance, and specifically for MRI, and the protocol of real-time imaging acquisition is affected by the long acquisition time (at least $20 \mathrm{~s}$ ), in which any motion on the gastric projection must be avoided to obtain a high-resolution image.
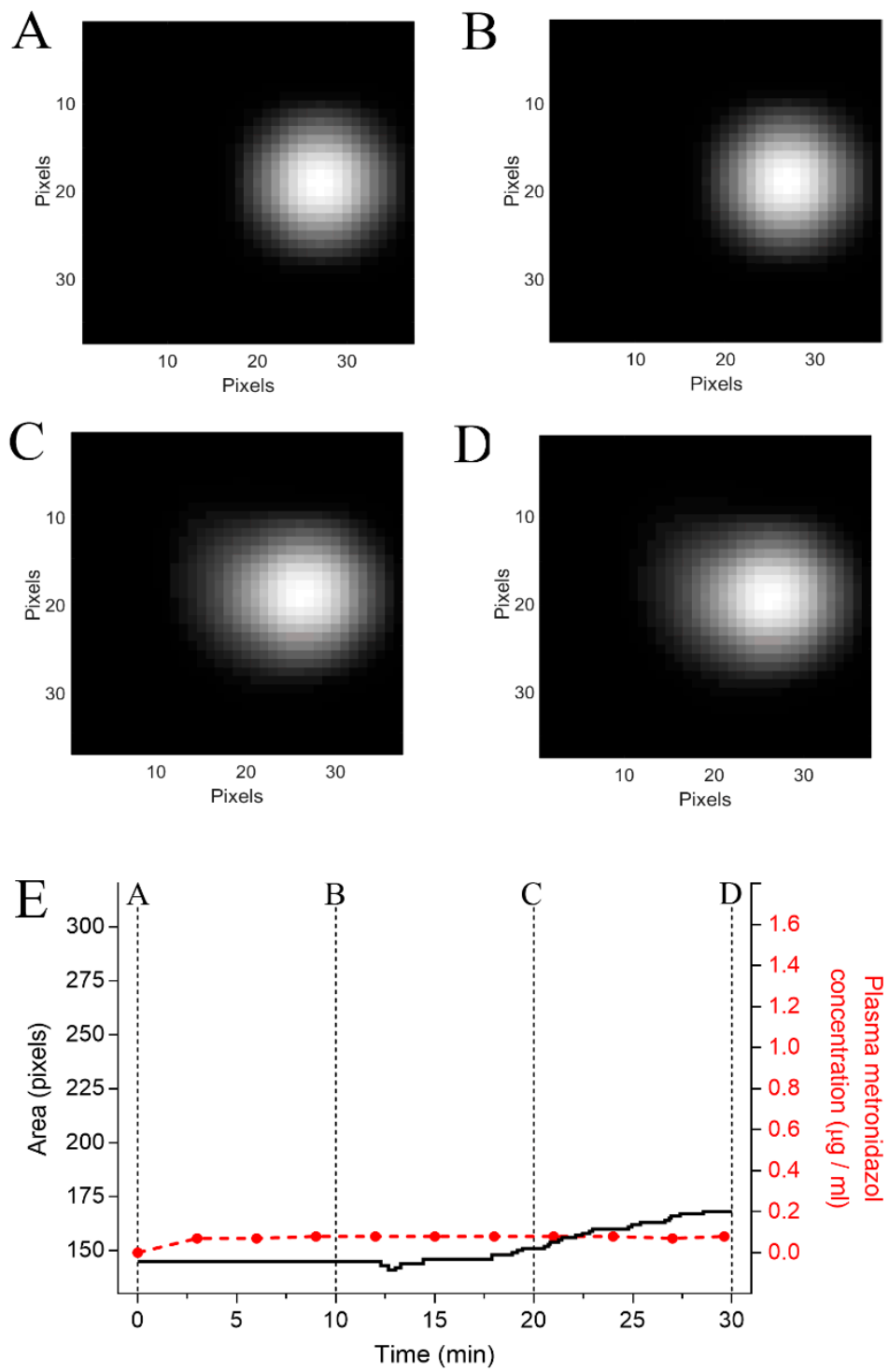

Figure 5. Pharmacomagnetography monitoring of the coated magnetic tablet after administration of omeprazole. (A) Magnetic images at $\mathrm{t}=0 \mathrm{~min},(\mathbf{B}) \mathrm{t}=10 \mathrm{~min},(\mathbf{C}) \mathrm{t}=20 \mathrm{~min}$, and $(\mathbf{D}) \mathrm{t}=30 \mathrm{~min}$ after coated magnetic tablet administration. (E) Quantification of the magnetic area and metronidazole concentration, the dotted lines indicate the time points in which A, B, C, and D were captured.

The MC-ACB system does not require electromagnetic shields, and for this reason, it is portable, versatile, and less expensive to implement $[19,50]$. However, in our study, the ACB system had a few drawbacks, such as the time limit of MC-ACB measurements (the volunteer must remain in an upright position for a long time after an overnight fast), spatial resolution, and the distance dependence of the signal, which restricts its 
application to volunteers with a low body mass index. Nevertheless, ACB is feasible for laboratory conditions, since it is portable and easily transportable between facilities to perform measurements [22].

\section{Conclusions}

The ACB system and the standard pharmacokinetics method allowed tablet movement characterization and delineated the release sites in the gastrointestinal tract. The ACB was suitable for determining the onset of the tablet's disintegration process. In the case of elevated gastric $\mathrm{pH}$ associated with the use of omeprazole, the evidence suggests that the bioavailability of metronidazole is influenced by its release in the wrong place when the tablet coating is ph-dependent.

Our study reinforced the advantages of pharmacomagnetography as an attractive tool to perform a multi-instrumental correlation analysis of the disintegration process and the bioavailability of a drug. The association with pharmacokinetic parameters enables the tablet's location at which the drug is released to be determined.

Based on our results, concomitant PPI administration with other drugs requires extensive investigation, which the ACB system may carry out through in vitro and in vivo analysis. In this way, our study showed the influence of omeprazole on tablets coated with E100.

Author Contributions: Conceptualization, G.A.S., L.A.C., L.A.P., R.B.O. and J.R.A.M.; methodology, D.W.P., G.S.R. and A.G.P.; software, G.G.A.B., A.G.P. and L.A.P.; validation, D.W.P., G.S.R., G.N.B. and E.G.S.; formal analysis, G.A.S., L.A.P., G.S.R. and E.G.S.; investigation, G.A.S., G.N.B., G.S.R. and G.G.A.B.; resources, G.A.S., L.A.P., G.N.B. and E.G.S.; data writing-original draft preparation, G.A.S., D.W.P., L.A.P. and L.A.C.; writing-review and editing, G.A.S., A.G.P., R.B.O. and J.R.A.M.; supervision, R.B.O., J.R.A.M. and A.G.P.; project administration, R.B.O. and J.R.A.M.; funding acquisition, J.R.A.M. and R.B.O. All authors have read and agreed to the published version of the manuscript.

Funding: This research was funded by FAPESP, grant number 2015/1492.3-9, CNPq, grant number 312074/2018-9, and INCT-FNA.

Institutional Review Board Statement: The study was conducted according to the guidelines of the Declaration of Helsinki and approved by the Ethics Committee of the School of Medicine, São Paulo State University (UNESP), according to the protocol approved by the (Certificate of Presentation for Ethical Appreciation: 41563015.3.0000.5411, Committee's technical opinion number: 986486, Data of Approval: 4 May 2015).

Informed Consent Statement: Informed consent was obtained from all subjects involved in the study.

Data Availability Statement: Almost all data are presented within the manuscript (figures and tables). The raw data presented in this study are available on request from the corresponding author.

Acknowledgments: We acknowledge Uilian Andreis for all technical support. This study was financed in part by the Coordenação de Aperfeiçoamento de Pessoal de Nível Superior-Brasil (CAPES).

Conflicts of Interest: The authors declare no conflict of interest.

\section{References}

1. Huanbutta, K.; Yunsir, A.; Sriamornsak, P.; Sangnim, T. Development and in vitro/in vivo evaluation of tamarind seed gum-based oral disintegrating tablets after fabrication by freeze drying. J. Drug Deliv. Sci. Technol. 2019, 54, 101298. [CrossRef]

2. Li, C.; Wang, J.; Wang, Y.; Gao, H.; Wei, G.; Huang, Y.; Yu, H.; Gan, Y.; Wang, Y.; Mei, L.; et al. Recent progress in drug delivery. Acta Pharm. Sinica. B 2019, 9, 1145-1162. [CrossRef]

3. Debotton, N.; Dahan, A. Applications of Polymers as Pharmaceutical Excipients in Solid Oral Dosage Forms. Med. Res. Rev. 2017, 37, 52-97. [CrossRef]

4. Silchenko, S.; Nessah, N.; Li, J.; Li, L.B.; Huang, Y.; Owen, A.J.; Hidalgo, I.J. In vitro dissolution absorption system (IDAS2): Use for the prediction of food viscosity effects on drug dissolution and absorption from oral solid dosage forms. Eur. J. Pharm. Sci. 2020, 143, 105164. [CrossRef]

5. Koziolek, M.; Gorke, K.; Neumann, M.; Garbacz, G.; Weitschies, W. Development of a bio-relevant dissolution test device simulating mechanical aspects present in the fed stomach. Eur. J. Pharm. Sci. 2014, 57, 250-256. [CrossRef] 
6. Koziolek, M.; Schneider, F.; Grimm, M.; Modebeta, C.; Seekamp, A.; Roustom, T.; Siegmund, W.; Weitschies, W. Intragastric pH and pressure profiles after intake of the high-caloric, high-fat meal as used for food effect studies. J. Control. Release 2015, 220, 71-78. [CrossRef] [PubMed]

7. Abuhelwa, A.Y.; Williams, D.B.; Upton, R.N.; Foster, D.J. Food, gastrointestinal pH, and models of oral drug absorption. Eur. J. Pharm. Biopharm. 2017, 112, 234-248. [CrossRef] [PubMed]

8. van Seyen, M.; Colbers, A.; Abbink, E.J.; Drenth, J.P.H.; Burger, D.M. Concomitant Intake of Coca-Cola to Manage the Drug-Drug Interaction Between Velpatasvir and Omeprazole Studied in Healthy Volunteers. Clin. Pharmacol. Ther. 2019, 106, 1093-1098. [CrossRef] [PubMed]

9. Bellia, G.F.; Gil-Ramirez, G.; Baron, M.G.; Croxton, R.; Gonzalez-Rodriguez, J. Analysis of omeprazole and esomeprazole obtained from traditional pharmacies and unlicensed internet websites using Raman spectroscopy, $1 \mathrm{H}-\mathrm{NMR}$ and chemometric analysis. Vib. Spectrosc. 2020, 106, 102996. [CrossRef]

10. Abuhelwa, A.Y.; Mudge, S.; Upton, R.N.; Foster, D.J.R. Mechanistic Assessment of the Effect of Omeprazole on the In Vivo Pharmacokinetics of Itraconazole in Healthy Volunteers. Eur. J. Drug Metab. Pharmacokinet. 2019, 44, 201-215. [CrossRef]

11. Ronchi, F.; Sereno, A.; Paide, M.; Sacre, P.; Guillaume, G.; Stephenne, V.; Goole, J.; Amighi, K. Development and evaluation of an omeprazole-based delayed-release liquid oral dosage form. Int. J. Pharm. 2019, 567, 118416. [CrossRef]

12. van der Bol, J.M.; Loos, W.J.; de Jong, F.A.; van Meerten, E.; Konings, I.R.; Lam, M.H.; de Bruijn, P.; Wiemer, E.A.; Verweij, J.; Mathijssen, R.H. Effect of omeprazole on the pharmacokinetics and toxicities of irinotecan in cancer patients: A prospective cross-over drug-drug interaction study. Eur. J. Cancer 2011, 47, 831-838. [CrossRef]

13. Li, W.; Zeng, S.; Yu, L.S.; Zhou, Q. Pharmacokinetic drug interaction profile of omeprazole with adverse consequences and clinical risk management. Ther. Clin. Risk Manag. 2013, 9, 259-271. [CrossRef]

14. Attia, T.Z.; Yamashita, T.; Tsujino, H.; Derayea, S.M.; Tsutsumi, Y.; Uno, T. Effect of Drug Combination on Omeprazole Metabolism by Cytochrome P450 2C19 in Helicobacter pylori Eradication Therapy. Chem. Pharm. Bull. 2019, 67, 810-815. [CrossRef]

15. Jaruratanasirikul, S.; Sriwiriyajan, S. Effect of omeprazole on the pharmacokinetics of itraconazole. Eur. J. Clin. Pharmacol. 1998, 54, 159-161. [CrossRef]

16. Maderuelo, C.; Lanao, J.M.; Zarzuelo, A. Enteric coating of oral solid dosage forms as a tool to improve drug bioavailability. Eur. J. Pharm. Sci. 2019, 138, 105019. [CrossRef] [PubMed]

17. Farooq, U.; Khan, S.; Nawaz, S.; Ranjha, N.M.; Haider, M.S.; Khan, M.M.; Dar, E.; Nawaz, A. Enhanced gastric retention and drug release via development of novel floating microspheres based on Eudragit E100 and polycaprolactone: Synthesis and in vitro evaluation. Des. Monomers Polym. 2017, 20, 419-433. [CrossRef]

18. Cora, L.A.; Romeiro, F.G.; Paixao, F.C.; Americo, M.F.; Oliveira, R.B.; Baffa, O.; Miranda, J.R. Enteric coated magnetic HPMC capsules evaluated in human gastrointestinal tract by AC biosusceptometry. Pharm Res. 2006, 23, 1809-1816. [CrossRef]

19. Weitschies, W.; Blume, H.; Monnikes, H. Magnetic marker monitoring: High resolution real-time tracking of oral solid dosage forms in the gastrointestinal tract. Eur. J. Pharm. Biopharm. 2010, 74, 93-101. [CrossRef] [PubMed]

20. Cora, L.A.; Americo, M.F.; Oliveira, R.B.; Serra, C.H.; Baffa, O.; Evangelista, R.C.; Oliveira, G.F.; Miranda, J.R. Biomagnetic methods: Technologies applied to pharmaceutical research. Pharm. Res. 2011, 28, 438-455. [CrossRef] [PubMed]

21. Cora, L.A.; Romeiro, F.G.; Stelzer, M.; Americo, M.F.; Oliveira, R.B.; Baffa, O.; Miranda, J.R. AC biosusceptometry in the study of drug delivery. Adv. Drug Deliv. Rev. 2005, 57, 1223-1241. [CrossRef]

22. Pinto, L.A.; Corá, L.A.; Rodrigues, G.S.; Prospero, A.G.; Soares, G.A.; de Andreis, U.; de Arruda Miranda, J.R. Pharmacomagnetography to evaluate the performance of magnetic enteric-coated tablets in the human gastrointestinal tract. Eur. J. Pharm. Biopharm. 2021, 161, 50-55. [CrossRef] [PubMed]

23. Soares, G.A.; Prospero, A.G.; Calabresi, M.F.; Rodrigues, D.S.; Simoes, L.G.; Quini, C.C.; Matos, R.R.; Pinto, L.A.; Sousa-Junior, A.A.; Bakuzis, A.F.; et al. Multichannel AC Biosusceptometry System to Map Biodistribution and Assess the Pharmacokinetic Profile of Magnetic Nanoparticles by Imaging. IEEE Trans. Nanobiosci. 2019, 18, 456-462. [CrossRef] [PubMed]

24. Khan, K.A. The concept of dissolution efficiency. J. Pharm. Pharmacol. 1975, 27, 48-49. [CrossRef] [PubMed]

25. Cora, L.A.; Andreis, U.; Romeiro, F.G.; Americo, M.F.; Oliveira, R.B.; Baffa, O.; Miranda, J.R. Magnetic images of the disintegration process of tablets in the human stomach by ac biosusceptometry. Phys. Med. Biol. 2005, 50, 5523-5534. [CrossRef]

26. Campos, M.L.; de Moura Alonso, J.; Dos Santos Martins, E.; Oliveira, J.A.; Hussni, C.A.; Peccinini, R.G. Ceftriaxone pharmacokinetics by new simple and sensitive ultra-high-performance liquid chromatography method. Diagn. Microbiol. Infect. Dis. 2017, 88, 95-99. [CrossRef]

27. Perkins, A.C.; Wilson, C.G.; Frier, M.; Blackshaw, P.E.; Juan, D.; Dansereau, R.J.; Hathaway, S.; Li, Z.; Long, P.; Spiller, R.C. Oesophageal transit, disintegration and gastric emptying of a film-coated risedronate placebo tablet in gastro-oesophageal reflux disease and normal control subjects. Aliment. Pharmacol. Ther. 2001, 15, 115-121. [CrossRef]

28. Corá, L.A.; Américo, M.F.; Romeiro, F.G.; Oliveira, R.B.; Miranda, J.R.A. Pharmaceutical applications of AC Biosusceptometry. Eur. J. Pharm. Biopharm. 2010, 74, 67-77. [CrossRef]

29. Mukaka, M.M. Statistics corner: A guide to appropriate use of correlation coefficient in medical research. Malawi Med. J. 2012, 24, 69-71. [PubMed]

30. Davit, B.M.; Kanfer, I.; Tsang, Y.C.; Cardot, J.-M. BCS Biowaivers: Similarities and Differences Among EMA, FDA, and WHO Requirements. AAPS J. 2016, 18, 612-618. [CrossRef] 
31. Cook, J.A.; Davit, B.M.; Polli, J.E. Impact of Biopharmaceutics Classification System-based biowaivers. Mol. Pharm 2010, 7, 1539-1544. [CrossRef] [PubMed]

32. Dressman, J.B.; Berardi, R.R.; Dermentzoglou, L.C.; Russell, T.L.; Schmaltz, S.P.; Barnett, J.L.; Jarvenpaa, K.M. Upper gastrointestinal (GI) pH in young, healthy men and women. Pharm. Res. 1990, 7, 756-761. [CrossRef] [PubMed]

33. Jessa, M.J.; Goddard, A.F.; Barrett, D.A.; Shaw, P.N.; Spiller, R.C. The effect of omeprazole on the pharmacokinetics of metronidazole and hydroxymetronidazole in human plasma, saliva and gastric juice. Br. J. Clin. Pharm. 1997, 44, 245-253. [CrossRef]

34. Kim, J.; Chun, J.; Park, J.Y.; Hong, S.W.; Lee, J.Y.; Kang, J.W.; Hwang, S.; Ko, S.-B.; Im, J.P.; Kim, J.S. Metronidazole-induced encephalopathy in a patient with Crohn's disease. Intest. Res. 2017, 15, 124-129. [CrossRef]

35. Katz, P.O.; Xue, S.; Castell, D.O. Control of intragastric $\mathrm{pH}$ with omeprazole $20 \mathrm{mg}$, omeprazole $40 \mathrm{mg}$ and lansoprazole $30 \mathrm{mg}$. Aliment. Pharmacol. Ther. 2001, 15, 647-652. [CrossRef] [PubMed]

36. Löbenberg, R.; Chacra, N.B.; Stippler, E.S.; Shah, V.P.; DeStefano, A.J.; Hauck, W.W.; Williams, R.L. Toward global standards for comparator pharmaceutical products: Case studies of amoxicillin, metronidazole, and zidovudine in the Americas. AAPS J. 2012, 14, 462-472. [CrossRef]

37. Yin, O.Q.P.; Giles, F.J; Baccarani, M.; le Coutre, P.; Chiparus, O.; Gallagher, N.; Saglio, G.; Hughes, T.P.; Hochhaus, A.; Kantarjian, H.M.; et al. Concurrent use of proton pump inhibitors or $\mathrm{H} 2$ blockers did not adversely affect nilotinib efficacy in patients with chronic myeloid leukemia. Cancer Chemother. Pharm. 2012, 70, 345-350. [CrossRef]

38. Rubbens, J.; Brouwers, J.; Tack, J.; Augustijns, P. Gastrointestinal dissolution, supersaturation and precipitation of the weak base indinavir in healthy volunteers. Eur. J. Pharm. Biopharm. 2016, 109, 122-129. [CrossRef] [PubMed]

39. Leavitt, E.; Lask, G.; Martin, S. Sonic hedgehog pathway inhibition in the treatment of advanced basal cell carcinoma. Curr. Treat. Options Oncol. 2019, 20, 1-12. [CrossRef]

40. Carpenter, R.L.; Ray, H. Efficacy and safety of sonic hedgehog pathway inhibitors in cancer. Drug Saf. 2019, 42, 263. [CrossRef] [PubMed]

41. Sandhiya, S.; Melvin, G.; Kumar, S.S.; Dkhar, S.A. The dawn of hedgehog inhibitors: Vismodegib. J. Pharmcol. Pharmcother. 2013, 4, 4-7. [CrossRef]

42. Zhou, J.; Quinlan, M.; Glenn, K.; Boss, H.; Picard, F.; Castro, H.; Sellami, D. Effect of esomeprazole, a proton pump inhibitor on the pharmacokinetics of sonidegib in healthy volunteers. Br. J. Clin. Pharm. 2016, 82, 1022-1029. [CrossRef]

43. Smelick, G.S.; Heffron, T.P.; Chu, L.; Dean, B.; West, D.A.; DuVall, S.L.; Lum, B.L.; Budha, N.; Holden, S.N.; Benet, L.Z. Prevalence of acid-reducing agents (ARA) in cancer populations and ARA drug-drug interaction potential for molecular targeted agents in clinical development. Mol. Pharm. 2013, 10, 4055-4062. [CrossRef] [PubMed]

44. Sun, W.H.; Ou, X.L.; Cao, D.Z.; Yu, Q.; Yu, T.; Hu, J.M.; Zhu, F.; Sun, Y.L.; Fu, X.L.; Su, H. Efficacy of omeprazole and amoxicillin with either clarithromycin or metronidazole on eradication of Helicobacter pylori in Chinese peptic ulcer patients. World J. Gastroenterol. 2005, 11, 2477-2481. [CrossRef] [PubMed]

45. Gee, S.C.; Hagemann, T.M. Palatability of liquid anti-infectives: Clinician and student perceptions and practice outcomes. J. Pediatric Pharmacol. Ther. 2007, 12, 216-223. [CrossRef] [PubMed]

46. Ruff, M.E.; Schotik, D.A.; Bass, J.W.; Vincent, J.M. Antimicrobial drug suspensions: A blind comparison of taste of fourteen common pediatric drugs. Pediatric Infect. Dis. J. 1991, 10, 30-33. [CrossRef]

47. Uchida, T.; Tanigake, A.; Miyanaga, Y.; Matsuyama, K.; Kunitomo, M.; Kobayashi, Y.; Ikezaki, H.; Taniguchi, A. Evaluation of the bitterness of antibiotics using a taste sensor. J. Pharm. Pharmacol. 2003, 55, 1479-1485. [CrossRef]

48. Keeley, A.; Teo, M.; Ali, Z.; Frost, J.; Ghimire, M.; Rajabi-Siahboomi, A.; Orlu, M.; Tuleu, C. In Vitro Dissolution Model Can Predict the in Vivo Taste Masking Performance of Coated Multiparticulates. Mol Pharm 2019, 16, 2095-2105. [CrossRef]

49. Al-kasmi, B.; Alsirawan, M.H.D.B.; Paradkar, A.; Nattouf, A.-H.; El-Zein, H. Aqueous and pH dependent coacervation method for taste masking of paracetamol via amorphous solid dispersion formation. Sci. Rep. 2021, 11, 8907. [CrossRef]

50. Weitschies, W.; Friedrich, C.; Wedemeyer, R.S.; Schmidtmann, M.; Kosch, O.; Kinzig, M.; Trahms, L.; Sorgel, F.; Siegmund, W.; Horkovics-Kovats, S.; et al. Bioavailability of amoxicillin and clavulanic acid from extended release tablets depends on intragastric tablet deposition and gastric emptying. Eur. J. Pharm. Biopharm. 2008, 70, 641-648. [CrossRef] 